\title{
Introducing Web 2.0: social search for health librarians
}

\author{
Eugene Barsky and Allan Cho
}

\begin{abstract}
Although social searching is not a new phenomenon, its features of collaboration, conversation, and interaction in a social space among users make it an imperative element of Web 2.0 technologies. The emerging popularity of folksonomies, with users generating their own labeling system, has allowed social searching to distinguish itself from traditional search engines such as Google and Yahoo. This paper discusses a number of social search tools, including Google Custom Search, del.icio.us, YouTube, and Flickr, tools that the authors find useful for the practice of a health information professional.
\end{abstract}

\section{Introduction}

In this article we continue the discussion of Web 2.0 applications for use by health librarians [1-4], with a focus on the notion of social search. In upcoming issues of the Journal of the Canadian Health Libraries Association, we will explore the use of wikis in health library settings and the advanced use of really simple syndication (RSS) feeds.

What is Web 2.0 anyway? Often defined by the technologies that are part of it, namely weblogs, wikis, podcasts, RSS feeds, and other Web services, Web 2.0 is often dismissed as a fad. However, by looking at these technologies to see what they have in common, a certain pattern emerges. Web 2.0 is transforming the Web into a space that allows users to create and share information online - a space for collaboration, conversation, and interaction - one that is highly dynamic, flexible, and adaptable [5].

A number of health librarians and health professionals have investigated social software in various areas of health informatics [6-8], with Canadian librarian Dean Giustini concluding that "Web 2.0 may be one of the most influential technologies in the history of publishing, as old proprietary notions of control and ownership fall away" [6]. The American librarian Elizabeth Connor suggests that "Medical librarians who lack understanding of the Web 2.0 ecosystem risk marginalization within present user communities and may miss opportunities to work collaboratively with colleagues and clientele" [8].

E. Barsky. ${ }^{1}$ Irving K. Barber Learning Centre, 1961 East Mall, Vancouver, BC V6T 1Z1, Canada (e-mail:

eugene.barsky@ubc.ca, blog:

http://weblogs.elearning.ubc.ca/physio/).

A. Cho. School of Library, Archival, and Information Studies, 6190 Agronomy Road, Suite 301, Vancouver, BC V6T 1Z3, Canada (e-mail: allancho@gmail.com, blog: http://www.allanslibrary.blogspot.com/).

${ }^{1}$ Corresponding author.
We will, therefore, continue our discussion about Web 2.0 by focusing on social search. Social search is frequently publicized as the next big thing after Google for improving information retrieval, relevance, and awareness. Chris Sherman once defined social search as "a collection of Internet wayfinding tools informed by human judgment. That judgment takes place in the form of tags, click-through activity, search history, and other actions" [9]. We see social search as Web search refined by a user's social circle, which might be their Web mates or colleagues.

Social search is not a new phenomenon, however. Sites that relied on users rather than computer algorithms to map the Web appeared in the mid-1990s. When Yahoo (www.yahoo.com) started, it was just a collection of sites, handpicked and organized by humans. Librarians' Internet Index (http://lii.org/) is another collection of Web sites selected and evaluated by information professionals. However, the arrival of broadband Internet has brought an explosion of sites that rely on folksonomies. Unlike the taxonomies used by our profession, folksonomies are labeling systems generated by the users and as such, have no authority control. A great example is del.icio.us (http://del.icio.us), the social bookmarking tool where users tag their selected Web sites for personal reuse and sharing. Allowing Web users to flag interesting content for the wider community is also very central to the news site Digg (http://digg.com/), the video site YouTube (www.youtube.com), and many others. Social search aims to shift power from Web publishers, who create and market the content, to everyday Internet users by examining their bookmarks or giving them tools to express their opinions.

But why would it work? Why would we use intermediaries rather than going to our favourite search engines and using commands and Boolean logic to get relevant results? Should we use social search after the regular "unsocial" search fails to provide us with good enough results?

We certainly use our social networks to ask questions, answer other people inquiries, search the Web, and discover interesting things. When you need a plumber, you can find 
one in the directory, but most of us do like to get a recommendation from someone who has employed the plumber personally. Is it the same with Web results? In this paper, we will discuss a number of social search tools that we find particularly useful for the day-to-day practice of the health information professional.

\section{Google Custom Search}

With its Custom Search Engine (www.google.com/coop), Google offers a customized search platform that makes it easy for anyone to offer a highly adaptive search engine, which is built on the foundations of a previous trial called Google Co-op. Unlike broad-based traditional search engines such as Google or Yahoo, which retrieve large numbers of documents using a Web crawler, "vertical search" engines send their spiders out to only highly refined databases (or Web sites). Thus, the indexes of vertical search engines contain only information about specific topics.

Using Google's Custom Search Engine, anyone can create a set of "subscribed sites", a service that lets people choose other non-Google vertical search engines to show at the top or in lieu of Google search result pages. Moreover, you can prioritize sites, giving more weight to some than to others. You can also manipulate the look and feel of the search box to integrate it with other design elements on your site. The tool is fully collaborative, allowing the creator to send invitations to people to co-build a particular search application. For example, our own PhysioSearch (available from our blog at http://weblogs.elearning.ubc.ca/physio/ or at http://tinyurl. com/yrx38h) was done by using Google custom search. Consulting with practicing physiotherapists in British Columbia, we created a tool that searches only for high quality health information with a physiotherapy focus. We achieved this by prioritizing results from certain sites, like MedlinePlus, PubMed, and the Canadian Health Network, and by allowing users to narrow down their results to particular areas (e.g., Canadian content or consumer health literature). To get a sense of how the search engine is used, Google provides good usage statistics, including the most popular queries entered by searchers.

\section{del.icio.us}

Although the primary use of del.icio.us (http://del.icio.us) is to store and retrieve bookmarks online, some of its features also make it a social search engine. By allowing users to create tags to organize and remember bookmarks, searching del.icio.us produces links that other people with similar interests have bookmarked. At the same time, tagging allows users to link to additional key terms saved by other users. For example, running a search on "vitamin C" yields the related tags "cancer", "health", "science", "medicine", and "food" (see http://tinyurl.com/ywjdk3). With social searching, del.icio.us allows searchers to access areas of the deep Web that may not be easily reached with a traditional search engine such as Google, including webcasts, podcasts, newspaper and magazine articles, and grey literature. Moreover, you can add to your particular area of interest by adding your own links to the community, which in essence, makes it "social". At the same time, del.icio.us retains a feature of traditional search engines, namely the relevancy ranking of search results. The more people who have chosen to remember a link, the higher the link will "rise" to the top of the results page.

\section{YouTube}

Although YouTube (www.youtube.com) is a popular free video-sharing Web site, which lets users upload, view, and share video clips, it can also serve as a social search engine. Because YouTube offers a tagging feature, it too produces results from a community of people using similar keywords. For example, a YouTube webcast of an arthroscopic rotator cuff repair procedure hosted by the US-based Aurora BayCare Medical Center (see http://tinyurl.com/2cbm63) gets tags that include "shoulder surgery", "rotator-cuff", "arthroscopic", "aurora", "sports-medicine", "medicine", "live-surgery", "emedicine", "sports", and "webcast". Since users can rate the videos based on their own assessments, search results from YouTube are, in fact, determined by its community of users, thus producing a real "social" element to online searching.

\section{Flickr}

Flickr (www.flickr.com) is a widely used image-sharing tool that manages digital photos. Similar to other social search tools, Flickr allows users to tag images with many specific nouns, verbs, and adjectives that describe the pictures. Flickr hosts users' photos on its own servers so that they are retrievable from anywhere over the Web. Flickr has an algorithm not unlike Google's PageRank that uses "interestingness" based on a formula of the number of views and the number of people who have "favourited" an image. Although it is a measure of the popularity of a photograph on Flickr, interestingness changes over time; today's top photo may not be ranked so high in the future. It is the community of users who determines relevancy.

\section{Conclusion}

In summary, the tools presented in this paper look promising and could potentially fit into many health care applications and scenarios. Even so, careful thinking, testing, and evaluation are still needed to establish best practice models for leveraging these emerging technologies to boost our teaching and learning productivity and to foster stronger communities of practice in health librarianship. We don't believe that social search will take off overnight; however, as the technologies develop, we should be ready to use and teach them.

\section{References}

1. Barsky E. Introducing Web 2.0: RSS trends for health librarians. J Can Health Libr Assoc. 2006 Winter;27(1):7-8.

2. Barsky E. Introducing Web 2.0: weblogs and podcasting for health librarians. J Can Health Libr Assoc. 2006 Spring;27(2):33-4.

3. Barsky E, Purdon M. Introducing Web 2.0: social networking and social bookmarking for health librarians. J Can Health Libr Assoc. 2006 Summer;27(3):65-7. 
4. Cho A. An introduction to mashups for health librarians. $J$ Can Health Libr Assoc. 2007 Winter;28(1):19-22.

5. Coombs KA. Building a library Web site on the pillars of Web 2.0. Computers in Libraries 2007;27(1):16-9.

6. Giustini D. How Web 2.0 is changing medicine. BMJ. 2006 Dec 23;333(7582):1283-84.

7. Kamel Boulos MN, Wheeler S. The emerging Web 2.0 social software: an enabling suite of sociable technologies in health and health care education. Health Info Libr J. 2007 Mar;24(1):2-23.

8. Connor E. Medical librarian 2.0. Med Ref Serv Q. 2007 Spring;26(1):1-15.

9. Sherman C. What's the Big Deal With Social Search? Search Engine Watch; 2006 Aug 15 [accessed 2007 Mar 16]. Available from http://searchenginewatch.com/showPage.html?page= 3623153. 
